\title{
Compounding pharmacies: how to navigate the new regulatory and business environment and ensure high quality, safe products, which are cost effective
}

\begin{abstract}
Compounding pharmacies are under new regulations and scrutiny from the FDA and state agencies. Large scale compounders, regional medical systems and small local hospitals face challenges implementing the recently amended section 503 of the Federal Food, Drug and Cosmetic Act. This law will cause significant changes to the compounding pharmacy business model and operations of hospital pharmacies. Flaws in previous compliance and regulatory regimen led to major safety issues. For example in 2012, the New England Compounding Center prepared drug that was contaminated, causing a deadly fungal meningitis outbreak in several states. This event triggered legislation that will impact the industry in the following ways:

i. The compounding pharmacies will need to change their business and compliance practices

ii. Implementation and enforcement of the law will result in increased costs and consolidation of large-scale compounding pharmacies.

iii. Hospitals that utilized outsourced compounding pharmacies will need to allocate more resources to ensure that drug products are sterile, potent, stable and pure.

iv. Improved quality and consistency of drug products and processes will result from the new law. Ensuring patient safety and reducing risk should be a top priority of compounding pharmacies and hospitals. The institutions that achieve compliance will succeed.
\end{abstract}

Keywords: compounding pharmacy, drug quality and security act, regulations, quality assurance
Volume I Issue I - 2014

\author{
Erik D Foehr \\ Senior Partner, Strategic Partners Consulting, USA
}

Correspondence: Erik D Foehr, Senior Partner, Strategic Partners Consulting, LLC, 1729 King Street, Suite 100, Alexandria,VA 22314, USA, Tel 4I53204689, Email Erik.Foehr@sp2lc.com

Received: December 01, 2014 | Published: December 20, 2014
Abbreviations: FDA, food and drug administration; GMP, good manufacturing practice; USP, united states pharmacopeia; IACP, international academy of compounding pharmacists; cGMP, Current Good manufacturing practice; ASHP, american society of health-system pharmacists

\section{Introduction}

\section{Navigating the new regulatory and business environ- ment}

Following the 2012 deadly outbreak of fungal meningitis that killed nearly 70 people across the county, the congress and president gave the FDA additional powers to regulate compounding pharmacies. ${ }^{1}$ On November $27^{\text {th }}, 2013$ the Drug Quality and Security Act was signed into law. ${ }^{2}$ The legislation is detailed under section 503A of the Federal Food, Drug and Cosmetic Act. The enforcement actions, public scrutiny and economic impact of the new law have been profound Compounding Pharmacies, drug companies, hospitals, doctors and patients need to understand the law and its implications.

According to the International Academy of Compounding Pharmacists (IACP), an industry trade group, there are over 50,000 pharmacies in the USA. The vast majority are local pharmacists providing routine services and preparation of doctor prescribed medicines. However, approximately 3,500 Compounding Pharmacies provide "advanced compounding services" that may include re- formulation, alternative dosages, new packaging and sale across state lines. ${ }^{3}$ These activities enter the realm of regulated drug manufacturing and will get the attention of the FDA in addition to state regulators.

The new law detailed in section 503B, defines certain compounders as "outsourcing facilities" that must comply with current Good Manufacturing Practice (cGMP). ${ }^{4}$ These companies will be inspected by the FDA according to a risk-based schedule (typically every 2 years). Further, these firms must report adverse events and provide the FDA with information about the drugs they compound. Sterility, stability, possible adulteration and other quality attributes of the compounded drugs will be evaluated. Sterile drugs for injection made from bulk drug substances are particularly high risk and will get additional attention. The FDA will inspect the facility; look for a robust quality control system, training records and other documentation. The methods of analyzing the drugs should be well established and where possible follow the United States Pharmacopoeia (USP) and FDA guidance's. Experienced consultants or full time quality professionals can establish the infrastructure needed to comply with the new regulatory regimen. Being ready for inspection by the FDA is critical for success.

According to the FDA.gov website, between October 2012 (when the New England Compounding Center issue) and June 2014, over 100 inspections, recalls and other actions have been taken against compounding pharmacies and labs. Fewer than one dozen actions occurred in the 4years prior to 2012. The greatly increased regulatory 
enforcement activity underscores the seriousness of the issue and focus of the FDA. ${ }^{5}$

Strangely, the new law does not require registration with the FDA That is controversial because some compounders can stay "under the radar". The firms that register will be preferred vendors for hospitals and doctors, but these companies may get more scrutiny.

As of June 2014, only 48 facilities have registered as human drug compounding outsourcing facilities (as defined by the new law). The registration may provide needed legitimacy to a Compounding Pharmacy, but it may also open the company up to inspection and enforcement. According to the FDA website, $70 \%$ of the registered firms have been inspected. The inspections resulted in 28 issued FDA Form $483 \mathrm{~s}$ and 5 warning letters. This is a very high rate of action. The bottom line is this: Registration with the FDA will increase the compounder's credibility, but be prepared for inspection and enforcement of the new law.

Compounding Pharmacies (Outsourcing Facilities) should get their house in order, establish quality systems, attain cGMP compliance and register with the FDA. These steps will improve the credibility of the industry and ultimately result in safer, better quality medicines. Companies that achieve the needed level of quality will garner a larger market share. Consolidation in the industry is likely and companies should position themselves for success.

\section{Economic impact to the industry and regulatory en- forcement}

Pharmaceutical compounding in the United States is a well established industry, generating over \$5billion in revenue and employing more than 100,000 people. ${ }^{6}$ These firms produce $3 \%$ of the medicines dispensed in the USA. In decades past the majority of medicines were compounded by pharmacists, but large drug companies found it more efficient and profitable to avoid customized dosing forms, so the percentage of drugs compounded has dramatically shrunk relative to 50years ago. But keep in mind that modern drug manufacturing is much more sophisticated and sterile drugs for injection are particularly high risk. Compounding pharmacies often provide adjusted dosage forms for at-risk populations such as children, pregnant women or people with allergies. Therefore, the risks to patient safety are higher and compounders are still responsible for the products they dispense. ${ }^{7}$ When the investigations and enforcement wrapped up on New England Compounding Center, the company filed for bankruptcy and issued a $\$ 100$ million settlement in $2013 .{ }^{8}$ This is an extreme example, but mistakes or poor quality control on the part of a compounding pharmacy company can cause significant harm to patients, their own reputation and the firm's bottom line. Getting issued an FDA Form 483 is a black eye on a company but can be addressed, however, the issuance of an FDA Warning Letter may spell the end of the business and in fact the FDA can shutter a business if they do not address deficiencies. These regulatory actions are made public on the FDA website and are required to be revealed when a client asks the company about its inspection record. Compounding pharmacies, hospitals, doctors and patients need to stay informed and put safety first.

\section{Discussion}

Recommendations to compounding pharmacies/hospitals

Apply the cGMP and USP tenants. Carefully review the design of the outsourcing compounding facility. This includes everything from the physical layout, security and environmental controls. A Quality Assurance unit will ensure compliance and training for the cGMP regulations. Quality control requires review of all manufacturing records for accuracy and proper study conduct. The American Society of Health-System Pharmacists (ASHP) and other organizations provide detailed guidelines on compounding sterile preparations. ${ }^{9}$ The compounded drugs need to be tested by a qualified analytical and microbiology group or outsourced testing lab. However, the testing lab should be registered with the FDA and comply with cGMP regulations. The FDA inspects testing labs on a risk based schedule and will detail any findings in an inspection report. ${ }^{10,11}$

The compounded drugs should have demonstrated identity, stability, purity, potency and sterility. Many analytical methods for compounded drugs are described in USP Monographs. The methods of analysis may require specialized instrumentation and expertise. New and complex biopharmaceuticals such as Avastin may require method development and validation because there is no official USP Monograph. Avastin is compounded for off-label use in treating macular degeneration. According to USP34/NF29 "new dosage forms must retain within specified limits and throughout its period of storage and use, the same properties and characteristics that it possessed at the time of its preparation". A compounding pharmacy must monitor the compounded drug for signs of instability. In some cases a beyonduse date may be assigned if the data and intended use support such a claim. $^{12}$

The facility should have an environmental monitoring system in place. This often requires custom built facilities with specialize engineering controls and a robust monitoring system. Raw material and finished products need to be adequately tracked, monitored and labeled. Often sophisticated information management software is required. Routine internal audits should be performed by a quality assurance professional. Hospitals that utilize outsourcing facilities should inspect and audit their manufacturing partners on a regular basis. The key recommendations are summarized here:

i. Comply with current Good Manufacturing Practice (cGMP)

ii. Anticipate Inspections on a risk based schedule

iii. Report adverse events and adhere to new labeling requirements

iv. Provide information about facility to regulators

\section{Conclusion}

\section{Future of the industry}

The compounding pharmacy industry will continue to expand due to the ever increasing number of new drugs and combination devices. As more block-buster drugs come off patent and generics move in, drug makers will pull back on manufacturing new dosage forms or specialty formulations. Specialty compounding pharmacies will fill this need. This presents opportunities for collaboration between big pharmaceutical companies and outsourcing facilities to exchange know-how and continue offering medicines to the public. In the near to mid-term expect more FDA enforcement actions on outsourcing facilities. The new requirements will increase costs and may result in fewer, but larger outsourcing facilities. The FDA GMP requirements for testing compounded drugs typically include sterility and endotoxin.

The sterility tests should follow the recommended USP $<71>$ gui- 
dance and specific analytical tests detailed in the drugs monograph (i.e. identity, purity, concentration and stability etc.). These tests often require dozens of drug samples for each batch produced and cost significant amounts of time and money. Small compounders may find it nearly impossible to make a profit when small batch sizes of multiple drug types are compounded. Therefore, compounders may merge to form larger entities or be forced to focus on the high demand, inexpensive products. This may worsen shortages faced with certain pharmaceuticals. Compounding Pharmacies that find the right formulae for success may look to expand and press for consolidation of facilities to reduce overhead.

\section{Acknowledgements}

None.

\section{Conflict of interest}

Author declares that there is no conflict of interest.

\section{References}

1. DeNoon DJ. What are compounding pharmacies? Meningitis outbreak from compounded drug raises questions over pharmacies. WebMD Health News. 2012.

2. One Hundred Thirteenth Congress of the United States of America. Drug Quality and Security Act. Washington, USA; 2013.

3. Hoey BD. The new compounding law and community pharmacy's future. Pharmacy Times, USA; 2014.
4. FDA Draft Guidance. Pharmacy Compounding of Human Drug Products Under Section 503A of the Federal Food, Drug, and Cosmetics Act. Center for Drug Evaluation and Research (CDER). USA; 2014.

5. FDA. FDA outlines expectations for human drug compounders, including registered outsourcing facilities. U.S. Food and Drug Administration, USA; 2014

6. Compounding Pharmacies in the US: Market Research Report. Australia: IBISWorld; 2014.

7. Reinberg S. FDA starts regulating compounding pharmacies. New powers designed to make specialty drugs safer for patients. Health Day Report, USA; 2013.

8. Clarke T. FDA would have greater authority over compounding pharmacies under proposed bill. USA: Reuters; 2013.

9. ASHP Board of Directors. Drug Distribution and Control: Preparation and Handling-Guidelines. ASHP Guidelines on Compounding Sterile Preparations. USA: ASHP; 2013.

10. FDA. FDA Implementation of the Compounding Quality Act. U.S. Food and Drug Administration, USA; 2014.

11. FDA. Compounding and the FDA: Questions and Answers. U.S. Food and Drug Administration, USA; 2013.

12. Allen LV. Chapter 1: Guidelines for Compounding Practices. In: Allen LV, editor. The Art, Science, and Technology of Pharmaceutical Compounding. USA: American Pharmacists Association; 2012. 